\title{
IMAGE, OR WHAT? AN ATTEMPT TOWARDS A HOLISTIC EXPLORATION
}

\author{
STANISŁAW PUPPEL \\ JOANNA PUPPEL
}

\begin{abstract}
The following is a proposition paper whose purpose is to try to provide a solid theoretical (modelling) background for research on image generation and image maintenance. As such, it is intentionally devoid of any experimental/empirical findings. And although we agree that model-reasoning is difficult to observe, we nevertheless utterly agree with Rosenblueth and Wiener's stance according to which 'scientific knowledge consists of a sequence of abstract models, preferably formal, occasionally material in nature (Rosenblueth/Wiener, 1945,320), who further also stated that 'the ideal model would be one which would cover the entire universe' (Rosenblueth/Wiener, 1945,320). We are, of course, convinced that material substance can and should be provided later on as research continues to accrue with reference to the model(s) proposed.
\end{abstract}

General assumptions which are put forth in the paper are the following:

1. image is pervasive in nature; in fact, in humans it is more pervasive than language. This is due to the fact that the visual-tactile modality is of fundamental significance in the daily conduct of the human species (see e.g. Fletcher, 1952; Pirenne, 1967; Schiffman, 1982; Gordon, 1989; Sekuler/Blake, 1994).

2. Owing to its pervasiveness, image may be approached holistically, that is, it may be likened to life, especially to its exteriorization within the bounds of the material and perceiving/acting human body.

3. The paper is based on some general theoretical orientations which may be summarized as the following:

- material positivism: within this orientation, the subject matter of research is the universal occurrence of embodiment/entitiation and its consequences,

dialectical constructivism: within this orientation, a human agent as an embodied entity/organism is assumed to be involved in a continuous process of constructing and changing images.

Key words: image, image design (imagopolis), whirlpool, wrapper, core, the law of embodiment, the principle of image power, the law of apparition, the principle of image facade 


\section{A holistic approach to image generation and image maintenance}

Following the general holistic approach signaled above, the discussion presented in the paper is organized around a holistic diagram which represents the total structure of image. More specifically, The diagram represents what is called here the 'Image Design' (abbreviated ID). The following points are emphasized:

(a) The Image Design (ID) presented below (Figure 1) is assumed to contain an overall structure of closely collaborating spheres whose overall outcome is the generation and maintenance of images.

(b) As a dynamic design, and following the Copernican formula, it may be referred to as representing a perspective based on movement, that is as applying the movements of the spheres in image generation and maintenance which may be named De revolutionibus orbium imaginum,

(c) As a dense concentration of closely interacting (and revolving) spheres and nodes, it may also be termed the Imagopolis.

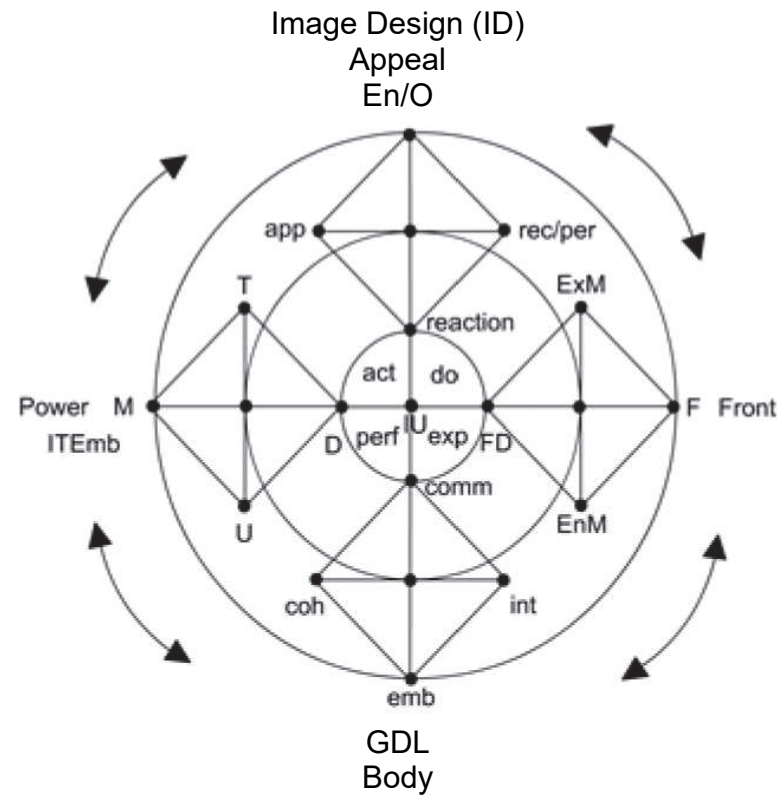

Figure 1. The Image Design (Imagopolis) as a concentration of closely interacting and revolving spheres and nodes (all the abbreviations are explained in the text)

The diagram represents three spheres which are collaborating closely and synergistically in the dialectic and synergy of image generation and image maintenance. They are the following: 
1. The Whirlpool which is meant to represent the external sphere and which shows punctuations (i.e. it is punctured) in four symmetrical points. The points of punctuation are the following: the body which is represented by the tetragon of the Grand Design of Life (GDL), The GDL is assumed to be at the base of all life and consists of 'embodiment' (emb) represented by the ontological phrase: 'here I am', 'cohabitation' (coh) represented by the ontological phrase: 'I am not alone', 'interactivity' (int) represented by the ontological phrase: 'I run/bump into others', and 'communication' (comm) represented by the ontological phrase: 'I have gathered resources and I share my resources with other entities/organisms' (for more information on the GDL see Puppel, 2016b; 2017), power which is represented by the tetragon of the Imperial Tetragon of Embodiment (ITEmb). The ITEmb is assumed to represent a consolidated framework for the functioning of any embodied agents via the domains of 'militancy' (M: meaning 'an entity is always militant'), 'trade-offs' (T: meaning 'an entity always exchanges information with other entities'), 'utility' (U: meaning 'an entity is always trying to maintain some degree of utility vis-a-vis other entities'), and 'display' (D: meaning 'an entity always displays itself in space and time') (for more information on the ITEmb see Puppel, 2009),

appeal which is represented by the tetragon of the particular entities (all living organisms, En/O). The tetragon is assumed to represent the functioning of any entity/organism via demonstrating the all-encompassing inter-species and intraspecies appeal ('app', for a discussion of appeal see e.g. Howard and Berlocher, 1998),

front which refers to the significance of the front in image generation and maintenance and which is represented by the tetragon containing the nodes of 'endo- makeup' (EnM, meaning 'I make up myself for my own satisfaction'), 'exo-makeup' (ExM, meaning 'I make up myself for my own benefit in the company of others'), 'front' ( $\mathrm{F}$, meaning 'It is the front/faęade of an entity/organism that matters in image generation and image reception/perception'), and 'front display' (FD, meaning 'It is the front display which I put at stake in the image universe'; on the importance of the front/faęade see Puppel, 2016a).

2. The Wrapper which is meant to represent the middle sphere. The sphere is assumed to be running through the centres of the four Tetragons described above. It is a provider of all the laws and principles which at any moment generate the infinity of images. It is assume that the following laws and principles are in operation in the Wrapper:

The Law of Embodiment

The Law of Embodiment is absolutely central to the generation and maintenance of images, for if there is 'something' (we may not know definitely why 
there is something out there), we may at least agree with Aristotle's underlying 'ontological categories' of: substance, quantity, quality, relation, place, time, position, condition, action, and affection as being of importance in the layout of any entity/organism (Aristotle, 1953; Barnes, 2015; see also Kant, 1998). If embodiment happens (and it does happen, as is attested by our senses), it assumes a variety of forms which are immediately subject to the Grand Design of Life (GDL) as defined above. The Law of Embodiment determines the framework in which all life on Earth is carried out within the bounds of the collective category of 'something', that is, within the bounds of embodied entities/organisms/agents. It also follows from the Law of Embodiment that entities/organisms as 'agents' are 'actors', 'doers', 'performers', 'expressors', and 'communicators', i.e. they are all capable of participating in an ever-encompassing behavioural complex of 'acting' (i.e. being able to act), 'doing' (i.e. being able to carry out an activity with an intention), 'performing' (i.e. being able to function in an observable manner vis-a-vis other entities/organisms), 'expressing' (i.e. being able to use various measurable means of expression), and 'communicating' (i.e. being able to share the resources which every entity/organism has been able to accumulate).

The Principle of Image Power

The Principle of Image Power, which follows the Law of Embodiment, entails that every single entity/organism/agent is both subject to and entitled to the maximum power of its existence (maximum impact) via an interplay of the parameters of the Imperial Tetragon of Embodiment (ITE) discussed above. In a favourable environment, both internal and external, every single parameter of militancy, tradeoffs, utility and display may obtain its highest possible values and may thus attain observable dominance over the remaining parameters. The extensions which may be obtained may thus include the following: militancy-dominant images, trade-offs-dominant images, utility-dominant images, and display-dominant images. Their impact may, therefore, differ considerably, although in reality no pure demonstrations of these extensions may be imagined. In fact, image power always involves an infinite variety of admixtures.

\section{The Law of Apparition}

The Law of Apparition entails that every single entity/organism/agent inherently and inextricably possesses some kind of appearance and is, subsequently, subject to reception (i.e. it is subject to sensual recognition carried out by other organisms/agents) and perception (i.e. it is subject to a complex of internal/mental processes within the bounds of the agents' mental representations; on mental operation and states see e.g. Watzl, 2017). 


\section{The Principle of Image Faęade}

Every entity/organism/agent basically (and predominantly) shows off the front. In this activity, every entity/organism/agent, especially the human agents, applies both endo- makeup and exo-makeup. More specifically, the endo-makeup is an operation of boosting the front of a human agent in order to increase his/her feeling of personal satisfaction and appeal to the feeling of aesthetics somehow connected with the sense of personal safety, whereas the exo-makeup operation is launched in order to produce an impression which is supposed to be beneficial to a given human agent in the ensuing receptive/perceptive processes of other agents, that is, 'in the eyes of other agents' (for a brief discussion of the indexicality of the human face as a part of the human front see J. Puppel, 2016).

\section{The Core}

The Core is the most dynamic and fastest of the spheres and which is assumed to contain the entire Image Universe (IU). It is also in the Core where all the images are generated and behave via the processes of: acting, doing, performing, expressing, and communicating, as defined above. The overall result of the workings of the Core is the entity's 'reaction' to internal/external environmental pressures, which comes in the production of an integrated (though ever-changing) image.

\section{Some conclusions}

Image generation and image maintenance constitute a bulk of extremely vital and complex processes which seem to span the entire bios. In the modelling approach represented and employed herein, image generation is both an intrinsic property of all beings, especially of the human species, and the result of the synergistic workings of the three spheres, the Whirpool, the Wrapper, and the Core. Moreover, in the model proposed here, the spheres are assumed to revolve, as it were, however, with varying speeds. Subsequently, the Whirpool as the external sphere is the slowest of the three, the Wrapper has medium speed, whereas the Core revolves with the highest speed. Jointly, they generate ever-changing images which most naturally conform to the proclivities of the ever-changing environment.

Moreover, it is assumed that the generation and maintenance of images is secured by the co-occurrence of the laws and principles which are considered to be operating within the

Image Design (Imagopolis). They are jointly responsible for the generation and maintenance of images. Finally, we emphasize that the material-positivist and dialectical-constructivist orientations which are sanctioned here constitute the most appropriate framework for a holistic/synergistic approach to image generation and image maintenance. 


\section{References}

Aristotle. 1953. Metaphysics. Oxford: Oxford University Press.

Barnes, J. (ed.). 2015. The complete works of Aristotle: the revised Oxford translation, one-volume digital edition. Princeton, N.J.: Princeton University Press.

Fletcher, H. 1952. Speech and hearing. (Revised edition). New York: van Nostrand.

Gordon, I.E. 1989. Theories of visual perception. New York: Wiley and Sons.

Howard, D.J. and S.H. Berlocher. 1998. Endless forms: species and speciation. Oxford/New York: Oxford University Press.

Kant, I. 1998. Critique of pure reason. Cambridge: Cambridge University Press.

Pirenne, M.H. 1967. Vision and the eye. London: Chapman and Hall.

Puppel, J. 2016. „Wskaźnikowość twarzy ludzkiej: krótki przegląd problematyki (Indexicality of the human face: a brief survey)". Scripta Neophilologica Posnaniensia XVI. 201-206.

Puppel, S. 2009. "Remarks on the sustainability of natural languages in the cultural-institutional perspective”. In: Puppel, S. and M. Bogusławska-Tafelska. (eds.). New pathways in linguistics 2009. Olsztyn: Uniwersytet Warmińsko-Mazurski. 275-286.

Puppel, S. 2016a. "Kuźnia Hefajstosa czyli krótki zarys teorii wizerunku w komunikacji człowieka" (The forge of Hephaistos, or a brief outline of the theory of image in human communication). Scripta Neophilologica Posnaniensia XVI. 109-124.

Puppel, S. 2016b. "The politics of performativity in transcommunication and its communicative fitness: towards a general outline". Scripta Neophilologica Posnaniensia XVI. 99-108.

Puppel, S. 2017. ECOLI[S] ${ }^{2}$ Essays and notes on ecolinguistic synergy and synthesis. Poznań: Zakład Graficzny UAM.

Rosenblueth, A. and N. Wiener. 1945. "The role of models in science". Philosophy of Science. 12.4. 316-321.

Schiffman, H.R. 1982. Sensation and perception. $2^{\text {nd }}$ ed. New York: Wiley and Sons.

Sekuler, R. and R. Blake. 1994. Perception. New York: McGraw-Hill.

Watzl, S. 2017. Structuring mind. The nature of attention and how it shapes consciousness. Oxford: Oxford University Press. 